\title{
Characterizing the Engineering Education Graduate Student Experience IN CANADA: RESEARCH DEVELOPMENT \& REFLECTIONS
}

\author{
Jillian Seniuk Cicek $^{a^{*}}$, Liz Kuley ${ }^{b}$, Patricia Sheridan ${ }^{c}$ and Robyn Mae Paul ${ }^{d}$ \\ ${ }^{\mathrm{a}}$ Faculty of Engineering, University of Manitoba, MB, Canada; ${ }^{\mathrm{b}}$ College of Engineering, University of Saskatchewan, SK, \\ Canada; ${ }^{\mathrm{C}}$ Faculty of Applied Science and Engineering, University of Toronto, ON, Canada; ${ }^{\mathrm{d}}$ Schulich School of \\ Engineering, University of Calgary, AB, Canada \\ umseniuk@myumanitoba.ca*
}

\begin{abstract}
Four Canadian Engineering Education students from the Universities of Manitoba, Saskatchewan, Toronto and Calgary have conceptualized conducting a national study to characterize the identities of graduate students studying Engineering Education in Canada. We developed the Canadian Engineering Education Student Identity Study (CEESIS). This is a mixed methods cross-case comparison research study designed to explore how Canadian Engineering Education graduate students' identities are formed through the intersection of our intellectual, institutional and networking academic experiences nested within our personal lives.

In this paper, we detail the realization, purpose, benefits, theoretical design and methodology of this study. The development of our theoretical framework and survey through the use of McAlpine's identity-trajectory construct is discussed. We conclude with individual personal reflections on how this research process has shaped our own growth as Engineering Education graduate students and how participation in this research group has influenced our understanding and identity of being Engineering Education graduate students and emerging Engineering Education researchers in Canada.
\end{abstract}

Keywords: Engineering Education; identities; graduate students in Canada; McAlpine's identity-trajectory construct; mixed methods cross-case comparison study

\section{INTRODUCTION \& MOTIVATION}

Engineering Education is a relatively new area of study in Canada that is slowly developing into a discipline, with its own association, national annual conference, research publications, and most recently, the interest in developing, and the establishment of some, graduate degree programs. Despite its fledgling state, and a limited number of formal programs, appeal from graduate students has expanded rapidly in the past several years. Subsequently, there are a large number of students in Canada working towards graduate degrees with a focus in Engineering Education.
Due to a recognition of the growth of this population, for the first time, at the Canadian Engineering Education Association (CEEA/ACEG) annual conference held in Hamilton, Ontario in June 2015, students studying Engineering Education were officially invited to identify themselves via a workshop conceived and run by two Engineering Education graduate students (Kuley and Paul, authors of this paper). The workshop was entitled Student Workshop: Meet and Greet and Formalizing a Student Society, and within a structured setting, students were encouraged to discuss their experiences, programs, and goals as Engineering Education scholars. It became evident through these discussions that this group is comprised of diverse individuals from across Canada, with distinct experiences, educational goals and needs, sharing some common, but mostly unique, experiences and stories. The degrees these students expect to be awarded are, for the most part, not formally specified as Engineering Education. Additionally, these degrees are being offered by a variety of departments and faculties, often in traditional Engineering departments. Consequentially, many of these students find themselves having to adapt to institutional structures and policies while being engaged in research that is often significantly different - both epistemologically and theoretically from their institutional peers.

These students show considerable initiative. The institutional structures in place for traditionally defined degrees do not always readily support the Engineering Education graduate students. The development of an identity as a graduate student and emerging researcher in Engineering Education is often heavily placed upon the student to construct, leading to highly unique pathways for each individual. It was clear that the diversity of expertise and experience revealed at the CEEA annual conference in 2015 warranted further exploration to understand how graduate students in Canada develop their identities as Engineering Education scholars. Understanding these identities are vital because identification "“.... is the process by which people come to define themselves, communicate that definition to others and use that definition to navigate their lives, work-wise or other" "[1]. It is the distinct perspective and identity of each student couched by this common goal - the study of 
Engineering Education in Canada - that is of interest in this study.

Four graduate students focusing their studies in Engineering Education (the authors of this paper) committed to this task. We are emerging researchers from the Universities of Manitoba, Saskatchewan, Toronto and Calgary who conceptualized conducting a national research study to characterize identity development of graduate students focusing on Engineering Education in Canada: the Canadian Engineering Education Student Identity Study (CEESIS). We generated a survey using McAlpine's construct of identity-trajectory as our theoretical framework $[1][2][3][4]$. This survey is designed to collect qualitative and quantitative data from graduate students in Canada who self-identify as currently completing an Engineering Education degree. Our objectives in this mixed-methods, cross-case comparison study are to explore how these graduate students' identities are formed through their intellectual, institutional and networking experiences, and to investigate how these academic circumstances are negotiated within students' personal lives, ultimately creating students' opportunities structures.

\section{PURPOSE, STAKEHOLDERS \& BENEFITS}

The purpose of this study is to characterize the identities of graduate students in Canada who are working on degrees with a focus in Engineering Education, and to explore how their experiences in these degree programs have influenced the development of their identities. Our research objectives were conceived to benefit three Engineering Education stakeholder groups: graduate students, faculty, and the Canadian agencies responsible for research funding.

\subsection{Engineering Education Student Stakeholders}

This research is purposed for the benefit of graduate students in Canada working on a degree focused on Engineering Education (although it may also have significance for Engineering Education students outside of Canada). Through the findings of this study, we aim to:

i. Understand what studies in Engineering Education look like in Canada through the construction of the identities of our Engineering Education graduate students;

ii. Understand how our experiences could influence the future trajectory of Engineering Education and Engineering Education research in Canada; iii. Build on our knowledge about Engineering Education and the opportunities and/or possibilities for Engineering Education students as emerging professionals in Canada; and

iv. Participate in reflective practice to better our understanding of the field by thinking deeply about our experiences in our respective programs in Canada.

\subsection{Engineering Education Faculty Stakeholders}

This research will enable faculty to take stock of what Engineering Education presently looks like in Canada through the construction of the identities of our graduate students. These data could potentially influence the direction of growth of Canadian Engineering Education degree programs based on the collective lived experiences of the Engineering Education graduate students within this community. Faculty's expanded understanding of Engineering Education could enhance Engineering Education programs, as well as other graduate degree programs. Examining the experiences and perspectives of our Engineering Education graduate students in Canada could help faculty better determine the intellectual and institutional supports these students may require to more effectively facilitate students' evolution into Engineering Education researchers. Moreover, these data could inform the development of HQP (Highly Qualified Personnel) opportunities, supporting faculty's grant applications.

\subsection{Canadian Funding Agencies}

Developing a more comprehensive understanding of our Engineering Education community could facilitate more effective, and thus successful, lobbying of grant and funding agencies for the financial support required for continued growth in this field. By representing the needs of our diverse community of Engineering Education students and emerging researchers, we endeavor to make the case to these agencies of the relevance and impact of this discipline to both the academic and industrialized worlds.

\section{THEORETICAL FRAMEWORKS}

\subsection{McAlpine's Identity-Trajectory Construct}

McAlpine's identity-trajectory construct was first introduced to one of our researchers during a keynote address by Anne Gardner at the Research in Engineering Education Symposium (REES) in Ireland in July 2015. Gardner spoke about her exploration of academic identity development, and how the research role was key to the development of the academic identity. Her research was 
grounded in McAlpine's identity-trajectory construct, where the intellectual, networking and institutional elements were woven together [2].

Identity-trajectory encapsulates other identity theories, including discourse-identity, activity theory [5], identity and story telling [6], and agency [1]. It emphasizes the importance and effect of a person's actions, past and present experiences, personal circumstances, institutional roles and career/future objectives through time [1]. It consists of three specific strands.

The intellectual strand focuses on learning both in the classroom and within the disciplinary space, and the contributions made as a result of that learning (i.e., journal publications, presentations, course projects, milestone exams and research findings) [3][4]. It is comprised of past experiences, personal agency, individual ability and personal circumstances [3][4].

The institutional strand is defined by a person's identity, based on affiliation and the role one plays within the university and in the field. Its components are the institutional structures and resources, and the responsibilities dictated by the role and resources available where the student is located [3][4]. Theoretically, institutions can support and/or constrain students.

The networking strand focuses on relationships - both past and present - and the resulting responsibilities that can enable or prevent an individual to meet/from meeting their current obligations [3][4]. The networking strand is defined as interpersonal and intertextual, the latter comprised of textual material in the field (i.e., the publications an individual reads) and the former the professional relationships, collaborations and organizations that an individual associates with or cultivates [3][4].

By intertwining the intellectual, institutional and networking strands, the individual's past and current personal context, agency, and academic development interact to create their 'horizons for action' [3][4]. The horizons for action - defined by what each person regards as possible and desirable - and the opportunities that exist - what is known or understood to be available career opportunities' at any given point in time - create a person's opportunity structures, ultimately linking the personal and academic components of identity [3][4]. As McAlpine et al. argue, "Any representation of identity will lack robustness without concern for mechanisms that recognize the influence of structure on agency" [4].

The CEESIS research group agreed that identitytrajectory was a concept relevant to the work we were proposing. McAlpine's construct offers a way to explore the personal components within the academic experience, emphasizing the importance of each individual's unique occurrences: "Investment in and commitment to academic work is influenced by much beyond the academic landscape...often overlooked [is the] individual variability in academic experience" [4]. McAlpine situates the academic identity within individual personal circumstance to explore the doctoral landscape: "The nesting of the academic within the personal, a central characteristic of identity-trajectory, ensures a comprehensive perspective in making sense of doctoral intentions, motivations, and decision-making" [3]. Thus, McAlpine's work on identity-trajectory provided a relevant theoretical framework for our CEESIS research and for the development of our survey instrument.

\subsection{Reflexivity: The Researchers as Participants}

This study cannot be presented without a brief discussion on reflexivity, and the role it must play in our research given our dual roles in this study as researchers, and as participants.

It is accepted as part of the paradigm of qualitative research that research is constructed. From the research question, to the chosen methods, to the collection of data, and the analysis and presentation of findings, qualitative research is shaped through the epistemological positionings and sociocultural interpretations that guide the decisions of the researchers [7][8][9]. Therefore, attempts to conduct qualitative research go hand-in-hand with a commitment to reflexive practice, so the researcher "make[s] visible to the reader the constructed nature of research outcomes" [8].

Further, as a function of this case study, we are researching ourselves: We are members of our sample population. Thereby, there is interplay between what we as researchers already perceive and have experienced as graduate students in Canada with a focus in Engineering Education, and how we conceived our study. Our experiences and perceptions will consciously and subconsciously have influenced how we designed our research study, and subsequently, our survey instrument.

We attempted to account for these substantial preconceptions by constructing a conceptual framework of graduate student identity development informed by McAlpine's identity-trajectory theory. We used this framework to develop our survey and we will use it to analyze resulting data. However, even the selection of the identity-trajectory construct, and the final design of this conceptual framework are explicitly informed by our own interpretations, values, and perceptions in regards to what it means to be a graduate student in Engineering Education in Canada. Positioning ourselves as participants in this research requires reflexivity; embracing this responsibility will demonstrate our credibility. As a result, we will "consciously acknowledge [our] values" [9] and attempt to "interpret our interpretations" [9][10] by presenting our research journey through, with, and by, the practice of reflexivity. 


\section{METHODOLOGY}

\subsection{Student Survey Development}

Investigating McAlpine's
$[3][4][11][12][13][14][15][16][17][18][19]$ led to
numerous discussions, debates, and iterative drafts via
emails, texts and face-to-face meetings on Google
Hangouts, and finally to the development of a conceptual
framework for our research (see Fig. 1).

\begin{tabular}{|c|c|c|c|c|}
\hline Links & Strands & \multicolumn{2}{|l|}{ Components } & Constructs \\
\hline \multirow{11}{*}{$\begin{array}{l}\text { The } \\
\text { academic } \\
\text { nested } \\
\text { within } \\
\text { personal } \\
\text { situation }\end{array}$} & \multirow{4}{*}{ Intellectual } & \multicolumn{2}{|c|}{ Past experiences } & $\begin{array}{l}\text { Credentials } \\
\& \\
\text { experiences } \\
\text { influence } \\
\text { present } \\
\text { intentions \& } \\
\text { imagined } \\
\text { futures }\end{array}$ \\
\hline & & \multicolumn{2}{|c|}{ Individual agency } & $\begin{array}{l}\text { Personal } \\
\text { desire \& } \\
\text { actions to } \\
\text { achieve goals }\end{array}$ \\
\hline & & \multicolumn{2}{|c|}{ Individual ability } & $\begin{array}{l}\text { Evidenced } \\
\text { by } \\
\text { achievement }\end{array}$ \\
\hline & & \multicolumn{2}{|c|}{ Personal circumstance } & $\begin{array}{l}\text { Broader life } \\
\text { experiences }\end{array}$ \\
\hline & \multirow{3}{*}{ Institutional } & \multicolumn{2}{|l|}{ Structures } & $\begin{array}{l}\text { Department/ } \\
\text { Program/ } \\
\text { College }\end{array}$ \\
\hline & & \multicolumn{2}{|l|}{ Resources } & $\begin{array}{l}\text { Advisor time } \\
\& \text { financial } \\
\text { support/ } \\
\text { Institutional } \\
\text { funding }\end{array}$ \\
\hline & & \multicolumn{2}{|c|}{ Responsibilities } & $\begin{array}{l}\text { Institutional } \\
\text { responsibility } \\
\text { due to } \\
\text { support }\end{array}$ \\
\hline & \multirow{4}{*}{ Network } & Intertextual & Texts & $\begin{array}{l}\text { Readings in } \\
\text { the field }\end{array}$ \\
\hline & & \multirow{3}{*}{ Interpersonal } & $\begin{array}{l}\text { Professional } \\
\text { relationships }\end{array}$ & $\begin{array}{l}\text { Colleagues, } \\
\text { peers, } \\
\text { faculty, } \\
\text { supervisors } \\
\end{array}$ \\
\hline & & & Organizations & $\begin{array}{l}\text { Professional } \\
\text { membership }\end{array}$ \\
\hline & & & Collaborations & $\begin{array}{l}\text { Internal \& } \\
\text { external } \\
\text { research } \\
\text { alliances } \\
\end{array}$ \\
\hline \multirow{2}{*}{\multicolumn{2}{|c|}{$\begin{array}{l}\text { Opportunity Structures: } \\
\text { Link between the } \\
\text { academic \& personal } \\
\text { identity }\end{array}$}} & \multicolumn{2}{|c|}{ Opportunities that exist } & $\begin{array}{l}\text { Known } \\
\text { career } \\
\text { opportunities }\end{array}$ \\
\hline & & \multicolumn{2}{|c|}{ Horizons for action } & $\begin{array}{l}\text { Personally } \\
\text { viable } \\
\text { options for } \\
\text { action }\end{array}$ \\
\hline
\end{tabular}

Fig. 1. Theoretical framework based on McAlpine's identity-trajectory construct.

In this structure, the intellectual, institutional and the network strands represent the academic experiences of an individual, and are positioned within one's personal circumstances. The embedding of the academic experiences within personal circumstances demarcates one's opportunity structures: An individual's horizons for actions linked to their perceived opportunities. Due to the diversity of the Engineering Education graduate student population, we determined it was important to utilize a framework that accounted for, and leveraged, these students' different life (i.e., academic and personal) positions and experiences.

Once this framework was constructed, it guided the creation of a bank of questions for a web-based survey instrument. Two researchers from the group originated the questions, fitting each question into its corresponding place within the framework, working individually and together (on Google Hangouts) as development required. One of the two researchers then designed the on-line instrument using FluidSurvey.

Following that stage of development, all four researchers were given the task to examine the on-line survey individually to document any questions, concerns and/or suggestions for revisions and improvements, and to determine the content (relevance and representativeness) validity of the instrument [20]. To achieve this, each researcher responded to the survey as would-be participants. Next, we met numerous times on Google Hangouts, working through each question on FluidSurvey while one researcher made the changes and another researcher scribed minutes and documented action items. Revisions included content, wording, organization and formatting issues. Items that required further consideration were tabled for the next meeting. Once this stage of development was complete, the two researchers who initiated the questions stepped back while the other two researchers dealt with the flow of the survey questions and some final organizational refinement.

Presently, the survey consists of 156 questions in a range of multiple-choice, Likert-style and open-ended forms, with 63 (40\%), $42(27 \%)$ and 29 (19\%) questions linked to the intellectual, institutional and networking strands respectively, and 22 (14\%) questions corresponding to opportunity structures (see Fig. 2). We have elected not to include sample questions from the survey for two reasons. First, at the writing of this paper, two institutions had not yet granted ethics approval for our study. Secondly, we expect some of our target population to be present at the CEEA/ACEG 2016 annual conference where we will present this paper. We do not want to risk contaminating our data by unveiling parts of our survey at this time.

The survey will be piloted by graduate students from the Faculty of Psychology at the University of Calgary, who are not part of our target population, in order for us to determine the face (survey layout), structural (processes of participant), substantive (scales) and content (relevance and representativeness) validity of the 


\begin{tabular}{|c|c|c|c|}
\hline & $\begin{array}{l}\text { Questions per } \\
\text { Strand (156) }\end{array}$ & & $\begin{array}{c}\text { Questions per } \\
\text { Component }\end{array}$ \\
\hline \multirow{4}{*}{ Intellectual } & \multirow{4}{*}{$63(40 \%)$} & Past experiences & 6 \\
\hline & & $\begin{array}{c}\text { Individual } \\
\text { agency }\end{array}$ & 35 \\
\hline & & Individual ability & 11 \\
\hline & & $\begin{array}{c}\text { Personal } \\
\text { circumstance }\end{array}$ & 11 \\
\hline \multirow{3}{*}{ Institutional } & \multirow{3}{*}{$42(27 \%)$} & Structures & 15 \\
\hline & & Resources & 20 \\
\hline & & Responsibilities & 7 \\
\hline \multirow{4}{*}{ Network } & \multirow{4}{*}{$29(19 \%)$} & Intertextual & 14 \\
\hline & & $\begin{array}{l}\text { Interpersonal } \\
\text { (Professional } \\
\text { relationships) }\end{array}$ & 9 \\
\hline & & $\begin{array}{c}\text { Interpersonal } \\
\text { (Organizations) } \\
\end{array}$ & 3 \\
\hline & & $\begin{array}{c}\text { Interpersonal } \\
\text { (Collaborations) }\end{array}$ & 3 \\
\hline \multirow{2}{*}{$\begin{array}{l}\text { Opportunity } \\
\text { Structures }\end{array}$} & \multirow{2}{*}{$22(14 \%)$} & $\begin{array}{c}\text { Opportunities } \\
\text { that exist }\end{array}$ & 13 \\
\hline & & $\begin{array}{l}\text { Horizons for } \\
\text { action }\end{array}$ & 9 \\
\hline
\end{tabular}

Fig. 2. Number of survey questions for each strand in the Identity-Trajectory framework constructed for study.

instrument [20]. One of us is responsible for disseminating the survey to these volunteers following ethics approval from the University of Calgary. Once we receive the pilot population's survey responses and feedback, we will do a final pass of revisions predissemination in order to enhance the survey's readability, decrease its completion complexity, and ensure its validity.

\subsection{Ethics}

Ethics approval for our study has been granted through the Education and Nursing Research Ethics Board (ENREB) at the University of Manitoba. The University of Saskatchewan reviewed the University of Manitoba ENREB application and approval, and subsequently granted their External Application for Behavioural Research Ethics approval. Ethics approval from the Universities of Toronto and Calgary is presently being sought. Once all four universities have granted ethics approval, the pilot phase of the survey will commence.

\subsection{Target Population \& Proposed Dissemination}

Our target population includes any graduate student in Canada who self-identifies as completing a degree in, or with, a focus in Engineering Education. Once the survey has been piloted and its validity determined, one researcher will email a request for participation and the survey link to the attendees of the CEEA/ACEG 2015 and 2016 (pending) student workshops. As well, a request and survey link will be posted on our Engineering Education Student Slack account, and, in seeking permission from the appropriate channels, on
Linked-In, and in the CEEA/ACEG student newsletter. Additionally, we will deploy snowball sampling by encouraging participants and faculty to send the request for participation and survey link to any graduate students who may not be on our contact list, but who are identified by participants and/or faculty as part of our target population.

Involvement in this study will be voluntary and confidential, and we will ask participants to refrain from writing their names, the names of their institution, or any other potentially identifying information on the survey. Participants will have access to the survey on FluidSurvey for approximately four weeks. This will give them ample time to revisit the survey as needed, as due to the length of the instrument, we anticipate participants appreciating the opportunity for more than one sitting to complete their responses. After our initial recruitment, we will send out one reminder, and then a final notification alerting participants when the survey site will close.

\subsection{Data Capture \& Proposed Analysis}

Data will be collected and stored on secure servers on the campus at the University of Saskatchewan and access to these data will be restricted to one member of the research team to ensure that confidentiality is maintained. This researcher will review all the data before the remaining members of the research group have access to the surveys. This will be done to ensure the information collected is confidential (e.g., any names of persons, programs, institutions are removed, etc.). Once data have been reviewed, the data will be securely sent to the whole research team, and all four members will be involved in data analysis.

Analysis will include both quantitative and qualitative consideration. Quantitative analysis will involve descriptive statistics, primarily serving to characterize the demographics of the student population studying Engineering Education. Two researchers will analyze the data that are conducive to a quantitative interpretation, corroborating their findings with the other two researchers.

A constant-comparative thematic analysis will be conducted on the conceptual framework of the identitytrajectory construct, our survey questions, and on the themes occurring from the survey participants' responses [21]. Two researchers will code (in vivo) all of the qualitative data independently, writing thick descriptions to support their findings [21], and then they will confer with each other to ensure intercoder agreement [22]. Once the codes and emerging themes have been agreed upon, both researchers will revisit the data to substantiate their findings, with the codes developed in the first pass informing their review of the data during the second pass. 
Following this second round of analysis and subsequent discussions, the remaining two researchers will be asked to corroborate the qualitative analyses and findings. We will use the themes from the data to adapt our conceptual framework at the end of the survey.

Once the quantitative and qualitative findings have been confirmed, the data set and analyses will be considered holistically within the identity-trajectory framework, and then reflexively in light of the researchers' own experiences, to ultimately characterize the identities of graduate students working on degrees with a focus in Engineering Education in Canada. The credibility of the findings will be supported by our indepth detailed analysis and description of each participant's responses, our holistic consideration of the qualitative and quantitative findings, our corroboration based on our own reflexive participation in the research, and on the debriefing of our interpretations with each other, and possibly other colleagues and/or advisors, who may be consulted for guidance [7][8][9][10][21][23].

At this stage, the findings will be reported, and plans for the continuation of the research will be considered and set.

\subsection{Reflective Responses and Continuous Reporting}

As part of our commitment to reflexivity and to our stakeholders, we decided as a team to document and report on each stage of this research process. With this endeavour, we intend to accomplish two things. We propose to bring credibility to our research study by examining our own identities as Engineering Education graduate students, and the influences of these identities on our roles as researchers, and vice a versa. Secondly, we aim to illuminate the complexity of conducting rigorous mixed methods Engineering Education research. We trust that through reporting early and often on our own reflections in this study, we can serve as an example of how some Engineering Education research is conducted, and highlight Engineering Education as a developing and credible research field in Canada.

\section{DISCUSSION}

In order to document our identity development as researchers through participation in this study, each member of this team has explored their perceptions and experiences through a written, reflective response. Of particular interest at this stage of our study is how our understandings and identities of being Engineering Education graduate students and emerging Engineering Education researchers in Canada have been shaped by this work [24].
The responses were completed individually, without deliberation with one another, and are included below exactly as each researcher has written. A reflection on our collective learning and on the similarities and differences of our experiences follow.

\subsection{Researcher's Reflections}

I feel like this is the first true qualitative research that I've conducted that has been consciously, and comfortably ground in theory from the outset. I thank this research team for that. Nevertheless, I attribute the ability to do so to where $\mathrm{I}$ am in the junction of my development: This wouldn't have been possible without my education thus far, and the groundwork lain by my advisor. A conscious attempt has been made to keep true to the steps of rigorous qualitative research: To practice it, if you will. Darn! I still should have read more. (But haven't I heard that from other academics before?) I also need to learn to keep a research journal on a daily basis. I can't afford to let these research processes slip away without trying to capture and reflect on them while they are still fresh - I must collect my interpretations along the way, like marbles in a glass jar, so that I can examine each while witnessing the development of the whole. I have revelled in the power and liberation that I feel in being able to conceive and create our own research as a graduate student. How we have formed our own professional - national! - network, and have recognized our individual strengths and capitalized on them. How we can commiserate as the nuances of graduate life creep upon us. How we all have 'paper writing season!' I imagine that this is what it would be like to be part of a cohort - difficult to find in Engineering Education. Or to be a new academic faculty member, striving to plant and fertilize research ground - and here we have been gifted this opportunity to cultivate our own research garden while under the protective umbrella of studentship. How thankful I am for being entrusted to do so - both by my research colleagues and by my advisor. I question: Is this all a function of being an Engineering Education graduate student, i.e., a student in a relatively new field/discipline? Or is this universal for all graduate students, as they grow into becoming full-fledged researchers? Also: Is how I experience things a-typical, or typical, of graduate students? Perhaps graduate students in the humanities? The way I think so differently from this group - they're all engineers. I'm wordy... is this a function of me not being an engineer? Or is this why I'm not an engineer? These questions, very specific to this field, have had airtime with my research group. It is these particulars of our experiences coupled with the typicals - their intersection - that we propose to explore. But we must remind ourselves that despite how similar our circumstances, they cannot be discarded as representative. Rather they must be presented as 
individual, and we must strive to investigate and present our unique stories in this light.

\subsection{Researcher's Reflections}

Working in a national team on engineering education research has really brought to my attention the challenges that exist in creating multi-institutional studies. As engineering educators there is a requirement of us to provide evidence to our colleagues warranting the innovations we wish to create around teaching and learning in our universities. To begin to found these innovations we really need to have a better understanding of the current state of teaching and learning, and a better understanding of who our students, and who we, are. The complexity of setting up the kind of studies that begin to provide this evidence in a broader context than a few classes at one university, is a challenge that I was not introduced to in my more traditional engineering research training. Learning to accept the timelines and hurdles that exist in creating, and often delaying, this type of research has certainly been a key learning. However, if we are going to be able to create any changes in funding or establish this field in Canada we need to work together, across institutions to be able to create national research findings.

\subsection{Researcher's Reflections}

Identity Trajectory Theory allows the researcher to connect intellectual, institutional, and network strands in each participant, acknowledging that their past experiences influence their future trajectory, or their identity construction. As a reflective tool, it has helped me understand my own development as a researcher; I have realized that it was through recognizing various opportunity structures and fostering networks that I stumbled into this research area, and that my story is not necessarily unique. In addition to helping me have a better understanding of my path to this relatively new field of study, Identity Trajectory Theory is useful in understanding engineering education research as a whole, because it will give us insight into the researchers who chose engineering education as their path. In looking at the unique strands and the interconnected threads that exist between engineering education graduate students in Canada that lead us to this field of study, we can better understand the research area, existing best practices, the type of student that may want to enter into this field, and areas that can be improved.

\subsection{Researcher's Reflections}

Working with this research team of individuals from across Canada helped me to appreciate the commonality of challenges faced across the country in engineering education graduate research. Informal chats and discussions with the team really helped me to reflect on my own degree and understand where it fits. Most importantly, these discussions provided me with the confidence in knowing why I should to be studying and researching within the faculty of engineering (regardless of how often it is questioned).

I am fortunate to have peers at my own University studying in engineering education. And even though we are segregated across many departments, I have a support network that I can turn to locally. The relationship built amongst the team allowed us to provide support to each other from across Canada, which was particularly valuable for those who do not have any peers at their home University. Overall, the endeavor has been extremely beneficial to me personally, and I hope that our work will help to provide further support to individuals studying in engineering education.

\subsection{Researchers' Reflections on Their Individual Reflections}

In reviewing our reflections on our experiences and perceptions of our collaborative research journey to date, we are intensely proud of the work that we have initiated and developed thus far. We firmly believe that we have made a sound decision to team together on this study. In our individual reflections we look at distinctly different areas of the experience and apply our unique analyses to them. These diverse viewpoints will, in the long run, afford us a more complete picture of the landscape of Engineering Education when we conduct our data analysis. It offers us a multiplicity of perspectives for debating the meaning and implications of our data and findings. Through this diversity, we will be able to explore and develop a more comprehensive understanding of our population.

We have had many long, but productive, debates to date about theoretical constructs that have substantially enhanced our understandings of our individual epistemologies and methodological preferences. We anticipate that this learning will only continue, and trust that documenting our processes will serve to enrich our experiences and knowledge, as well as inform those starting out in the field, and even those already in the field, about one of the avenues down which we can tread to conduct Engineering Education research.

\section{NEXT STEPS}

Based on the findings from the survey data, the researchers are anticipating collecting additional qualitative data, likely conducting an auto-ethnographical exploration in order to construct narratives to describe 
the identities of graduate students with a focus in Engineering Education in Canada.

We intend to present our initial findings from the survey data at the CEEA/ACEG annual conference in 2017. Additionally, we plan to write at least one journal article to showcase Engineering Education student identities in Canada.

\section{CONCLUSIONS}

We are emerging scholars in Engineering Education from the Universities of Manitoba, Saskatchewan, Calgary and Toronto who have conceptualized conducting a national mixed methods, cross-case comparison research study to characterize the identities of graduate students focusing on Engineering Education in Canada: the Canadian Engineering Education Student Identity Study (CEESIS). We developed a survey using a theoretical framework generated using McAlpine's identity-trajectory construct. This survey is designed to collect quantitative and qualitative data from graduate students in Canada who self-identify as currently completing an Engineering Education graduate degree. Our objectives are to explore how these graduate students' identities are formed through the construction of their intellectual, institutional and networking experiences, and to investigate how these academic experiences, nested within their personal lives, create their opportunity structures.

To explore the identities of graduate students in Canada who self-select as currently completing an Engineering Education degree has been an incredibly rich research experience for us thus far. We still have much to do, and yet we feel that we have already accomplished a great deal. We are honing our research skills; we are creating and interacting within our own professional networks; and we are attempting to influence the growth of a discipline in Canada at its educational inception. To be in the position to experience and navigate this path speaks to our individual agency and to our rich opportunity structures. We are very fortunate to live in Canada during this evolutionary development in Engineering Education, and to be in the position to take advantage of the opportunities that this affords. Our participation in this group has shaped our growth as Engineering Education graduate students and our understandings and identities of being Engineering Education researchers. We trust that through our research activities, we will collect rich data for Engineering Education stakeholders in Canada, to substantiate the importance of, and boost the growth of, the field of Engineering Education in our country.

\section{Acknowledgements}

The authors would like to thank Sean Maw for his support and collaboration during the CEEA/ACEG 2015 student workshop, and Brain Frank, Jake Kaupp and Susan McCahan for fielding some of our queries and offering their support. We would like to thank all of our academic advisors for their trust and backing as we conduct this research. We thank all persons who have provided us with the resources to pursue this research and attend the CEEA/ACEG 2016 annual conference. And finally, we thank one another for the opportunity to participate in this unique and profound research collaboration.

\section{References}

[1] Lauren D. Thomas, "Identity-trajectory as a theoretical framework in engineering education research," in Proc. American Society for Engineering Education Annual Conference and Exposition: 360 Degrees of Engineering Education, ASEE121, (Indianapolis, IN 15-18 June 2014), 11 pp., 2014.

[2] Anne Gardner and Keith Willey, 'Engineering academics' identity transitions in becoming established engineering education researchers," in Proc. Research in Engineering Education Symposium Conf.: Translating Research into Practice, REES6, Brian Bowman (ed.) (Dublin, Ireland; 1315 July 2015), 9 pp., 2015.

[3] Lynn McAlpine, "Identity-trajectories: Doctoral journeys from past to present to future," Australian Universities Review, vol. 54, no. 1, pp. 38-46, 2012. Available as of August 8, 2015 from http://eric.ed.gov/?id=EJ968518

[4] Lynn McAlpine, Cheryl Amundsen, and Gill Turner, "Identity-trajectory - Reframing early career academic experience," British Education Research Journal, vol. 40, no. 6, pp. 952-969, 2014. Available as of August 4, 2015 from

http://onlinelibrary.wiley.com/doi/10.1002/berj.3123/abstrac

[5] Marie C. Paretti, "Teaching communication in Capstone Design: The role of the instructor in situated learning," Journal of Engineering Education, vol. 97, no. 4, pp. 491503, 2008.

[6] Cheryl Allendoerfer, Ken Yasuhara, Robin Adams, Dawn Williams, Tori Rhoulac Smith, and David Socha, "Storytelling in engineering education," in Proc. American Society for Engineering Education Annual Conference and Exposition: ASEE115, (Honolulu, Hawaii 24-27 June 2007), 17 pp., 2007.

[7] Susan Mathieson, "Developing academic agency through critical reflection: A sociocultural approach to academic induction programmes," International Journal for 
Academic Development, vol. 16, no. 3, pp. 243-256, 2011. Available as of April 18, 2016 from

http://dx.doi.org/10.1080/1360144X.2011.596730

[8] Michelle Ortlipp, "Keeping and using reflective journals in the qualitative research process," The Qualitative Report, vol. 13, no. 4, pp. 695-705, 2008. Available as of April 18, 2016 from http://nsuworks.nova.edu/tqr/vol13/iss4/8

[9] Lisa Anderson, "Reflexivity," in The SAGE Dictionary of Qualitative Management Research. London, England: SAGE Publications, 2008, 5 pp. \{ISBN: 9780857020109\} Available as of April 18, 2016 from http://dx.doi.org/10.4135/9780857020109.n86

[10] Mats Alvesson and Kaj Skoldberg, Reflexive Methodology: New Vistas for Qualitative Research, $2^{\text {nd }} E d$. London, England: SAGE Publications, 2009, 350 pp.

[11] Lynn McAlpine and Cheryl Amundsen, "Identity and agency: pleasures and collegiality among the challenges of the doctoral journey," Studies in Continuing Education, vol. 31, no. 2, pp. 109-125, 2009. Available as of April 19, 2016 from http://dx.doi.org/10.1080/01580370902927378

[12] Lynn McAlpine and Anila Asghar, "Enhancing academic climate: doctoral students as their own developers," International Journal for Academic Development, vol. 15, no. 2, pp. 167-178, 2010. Available as of April 19, 2016 from http://dx.doi.org/10.1080/13601441003738392

[13] Lynn McAlpine and Cheryl Amundsen, "Making meaning of diverse experiences: Constructing an identity through time," in Doctoral Education: Research-Based Strategies for Doctoral Students, Supervisors and Administrators. Netherlands: Springers, 2011, pp. 173-183. Available as of April 19, $2016 \quad$ from http://link.springer.com/chapter/10.1007/978-94-007-05074 10/fulltext.html\#copyrightInformation

[14] Lynn McAlpine and Lisa Lucas, "Different places, different specialisms: similar questions of doctoral identities under construction," Teaching in Higher Education, vol. 16, no. 6, pp. 695-706, 2011. Available as of April 19, 2016 from http://dx.doi.org/10.1080/13562517.2011.570432

[15] Lynn McAlpine, "Academic work and careers: Relocation, relocation, relocation," Higher Education Quarterly, vol. 66, no. 2, pp. 174-188, 2012.

[16] Lynn McAlpine, "Shining a light on doctoral reading: Implications for doctoral identities and pedagogies," Innovations in Education and Teaching International, vol. 49, no. 4, pp. 351-361, 2012. Available as of April 19, 2016 from http://dx.doi.org/10.1080/14703297.2012.728875

[17] Lynn McAlpine and Cheryl Amundsen, "Challenging the taken-for-granted: How research analysis might inform pedagogical practices and institutional policies related to doctoral education," Studies in Higher Education, vol. 37, no. 6, pp. 683-694, 2012. Available as of April 19, 2016 from http://dx.doi.org/10.1080/03075079.2010.537747

[18] Lynn McAlpine and Gill Turner, "Imagined and emerging career patterns: Perceptions of doctoral students and research staff," Journal of Further and Higher Education, vol. 36, no. 4, pp. 535-548, 2012. Available as of April 19, 2016 http://dx.doi.org/10.1080/0309877X.2011.643777

[19] Lynn McAlpine and Esma Emmioğlu, "Navigating careers: perceptions of sciences doctoral students, post-PhD researchers and pre-tenure academics," Studies in Higher Education, vol. 40, no. 10, pp. 1770-1785, 2015. Available as of April 19, 2016 from http://dx.doi.org/10.1080/03075079.2014.914908

[20] David M. Miller and Robert L. Linn, "Valid performancebased assessments," Applied Psychological Measurement, vol. 24, pp. 367-378, 2000. DOI: $10.1177 / 01466210022031813$. Available as of January 29, 2015 from http://apm.sagepub.com/cgi/content/abstract/24/4/367

[21] John W. Creswell, Qualitative Inquiry and Research Design: Choosing Among Five Approaches, 3rd ed. L.A., CA: Sage, 2013, 448 pp.

[22] John W. Creswell, Research Design: Qualitative, Quantitative, and Mixed Methods Approaches, $4^{\text {th }}$ ed. L.A., CA: Sage, 2014, 273 pp. \{ISBN: 978-1-4522-2610-1\}

[23] Marcia Friesen, Lynn Taylor, and Ron Britton, "A qualitative study of a course trilogy in Biosystems engineering design," Journal of Engineering Education, vol. 94 , no. 3, pp. 288-296, 2005.

[24] Patrick Alexander, Susan Harris-Huemmert, and Lynn McAlpine, "Tools for reflection on the academic identities of doctoral students," International Journal for Academic Development, vol. 19, no. 3, pp. 162-173, 2014. Available as of April 19, 2016 from http://dx.doi.org/10.1080/1360144X.2013.817333 